\title{
The relationship between moisture or mould observations in houses and the state of health of their occupants
}

\author{
O.M. Koskinen, T.M. Husman, T.M. Meklin, A.I. Nevalainen
}

The relationship between moisture or mould observations in houses and the state of health of their occupants. O.M. Koskinen, T.M. Husman, T.M. Meklin, A.I. Nevalainen. (C)ERS Journals Ltd 1999.

ABSTRACT: This work was conducted in order to study how the health of adults is affected by the presence of moisture or mould in the home.

A random sample of 310 houses in Finland was studied during the years 1993-1994. The houses were investigated for visual signs of moisture by a surveyor, and observations of mould were reported by the occupants. A moisture problem was observed in $52 \%$ and a mould problem in $27 \%$ of the houses. Health data was collected by means of a postal questionnaire from 699 adults.

Exposure to moisture was significantly associated with sinusitis, acute bronchitis, nocturnal cough, nocturnal dyspnoea and sore throat, and the exposed inhabitants had significantly more episodes of common cold and tonsillitis. Exposure to mould was significantly associated with common cold, cough without phlegm, nocturnal cough, sore throat, rhinitis, fatigue and difficulties in concentration.

Building-related moisture or mould increased the risk of upper and lower respiratory infections and symptoms as well as of nonrespiratory symptoms. Eur Respir J 1999; 14: 1363-1367.
National Public Health Institute, Division of Environmental Health, POB 95, SF70701 Kuopio, Finland.

Correspondence: A. Nevalainen, National Public Health Institute, Division of Environmental Health, POB 95, SF-70701 Kuopio, Finland Fax: 35817201155

\section{Keywords: Adult}

cross-sectional study

health survey

indoor air quality

respiratory symptoms

respiratory tract infections

Received: March 181998

Accepted after revision August 41999

This work was supported by a grant from the Yrjö Jahnsson Foundation, Finland and the Ministry of Social Affairs and Health.
Adverse health effects associated with damp or mouldy housing have been frequently reported since 1981 in a total of 32 studies, e.g. in the UK, the Netherlands, Canada, Finland and Sweden. Most studies have reported the health effects in children, but 12 contain data concerning adults [1-12]. The types of symptom reported by adults, which were associated with damp or mouldy housing, vary widely, ranging from respiratory symptoms such as blocked nose [5], cough and phlegm [7], and wheezing with breathlessness [1] to nonspecific symptoms such as nausea, vomiting, backache, fainting and bad nerves [5]. In an earlier study by the authors' group, both respiratory and nonrespiratory symptoms were reported to be strongly associated with living in a damp home [11].

In these earlier studies in adults, the exposure to damp or mouldy housing was verified using either questionnaires $[1,6-8,11]$, or indoor air measurements, or samples of mould patches [9], or a surveyor's assessment of moisture and mould [2], or a combination of those methods [3-5, 10]. Thus, the exposure assessment may be based on measurements of moisture or humidity, sampling and analysis of the microbiological status of the building or on surrogates, such as visual inspection of moisture or mould.

Moisture behaviour in buildings is to some extent dependent on climatic conditions. In Scandinavia, the relative humidity of indoor air is usually low, $<40 \%$ for most of the year due to the cold outdoor temperatures [13]. Thus, the condensed water or microbial growth found on window panes or other such phenomenon regarded as "normal" in more humid climates is far from normal in the cold climate. The structures in buildings are generally dry because of efficient insulation and the long heating season, up to 8 months each year. However, moisture problems occur within the structures, caused by leakages, capillary movement of soil water or condensation in cases of insufficient ventilation or inadequate insulation. This moisture accumulation often promotes microbial growth in structures and/or finishing materials, leading to particulate and gaseous emissions into indoor air. The characterization of exposure by means of measuring these emissions is extremely labour-intensive [14]. The cases in which there are dry indoor air, dampness and mould are not always visible, but the moisture accumulation into the structures is more readily seen, as visible signs of colour change or other such deterioration in the material. A standardized surveillance method for the preliminary screening of moisture faults, which is based on visual observations made by a building professional and supplemented with surface moisture recorders, has been developed. In addition, occupants are interviewed as to their own personal experience, observations and knowledge of their houses' usage and damage history. This method has been used to assess the prevalence of moisture problems in the housing stock [15].

The aim of this study was to evaluate which health problems were associated with observations of moisture made by an independent surveyor or with observations of mould reported by occupants. The results in adults are reported in this paper, whereas the findings in children have been presented separately in the second part of the study [16]. 


\section{Materials and methods}

A random sample of 310 detached or terraced houses in four Finnish cities were selected from building registers into a cross-sectional study. The houses were selected from different construction decades $(1950-1980)$ to ensure that the study material was representative of different periods of building practices in Finland. Data were collected during the years 1993-1994. Exposure was defined in two alternative ways: 1) visual observations of moisture by an independent surveyor, a building professional, and 2) visual or odour-based observations of mould by the occupants.

A total of 699 adults, $\geq 16$ yrs of age, were included in the study. The occupants' health data were collected by means of a self-administered postal questionnaire before the site visit of the surveyor. The questionnaire was modified from questionnaires used in other Finnish studies concerning respiratory diseases and symptoms [17, 18]. The questionnaire comprised questions regarding personal and environmental characteristics (25 questions), the occurrence of respiratory infections and symptoms (22 questions), allergic symptoms and asthma (nine questions), the presence of nonrespiratory symptoms and chronic diseases (19 questions), doctor visits, hospitalization and sick leave (four questions) and use of medication (two questions) during the past 12 months. In all, 81 questions provided detailed health data, and, of these, 22 items were studied as health outcomes and 10 as baseline characteristics. Several of the items studied were combinations of original questions. The health data were obtained from all the occupants of the 310 houses and thus the response rate was $100 \%$.

After the health survey, the occupants were contacted by telephone by the surveyor and the site visit was arranged. The houses were visually investigated for signs of moisture by civil engineers who were specially trained for this purpose [15]. The observations recorded were, for example, signs of leakage, moist spots, detachment of paint or other surface material and deformation or discouloration of wood or other such material. The building constructions were not dismantled nor were any samples taken. A building-related questionnaire was filled in by the surveyor based on these observations and completed by interviewing the occupants regarding their observations on moisture or mould and the house's history concerning major repairs, accidental leaks, etc.

\section{Definition of the exposure}

Exposure was defined in two different ways. First, exposure was defined as moisture faults observed by the surveyor and the houses were classified according to this criterion. The houses with no observations of moisture or with observations of minimal moisture spots, assessed to be of no consequence were regarded as "moisture absent" and the houses with observations of moisture were regarded as "moisture present". Consequently, according to this definition of exposure, the occupants of the houses classified as "moisture absent" formed the nonexposed group and the occupants of the houses classified as "moisture present, were the exposed group.
Secondly, exposure was defined and the houses classified based on the occupants' observations on past or present mould growth or mould odour, which they reported in the interview. In houses with more than one occupant, the opinion of the one responsible for the maintenance of the house was used for classification. The houses with no visible mould growth or mould odour were regarded as "mould absent", whereas the houses with visible mould growth on building constructions or mould odour were defined as "mould present". Consequently, the occupants of the houses with "mould absent" formed the nonexposed group and the occupants of the houses with "mould present" were the exposed group.

\section{Statistical analysis}

The data were analysed using SPSS/PC+ (SPSS, Inc., Chicago, IL, USA). Dichotomous variables were investigated using the Chi-squared test and the risk related to exposure was assessed by means of multivariate logistic regression models. The results were adjusted for age, sex, smoking, doctor-diagnosed allergy, indoor pets and atopic predisposition. The occupants were determined as having an atopic predisposition if they reported any of the atopic diseases enquired about, i.e. seasonal allergic rhinitis, asthma and atopic dermatitis. The differences in the means of variables were determined using the t-test for independent samples.

\section{Results}

In the first phase, exposure was defined as "moisture present" or "moisture absent", as observed by the surveyor. The housing characteristics of the houses with observations of moisture, "moisture present" $(\mathrm{n}=160)$, and with no observations of moisture, "moisture absent" $(n=150)$, are presented in table 1 . In $52 \%$ of the houses, moisture was observed by the surveyor. In $86 \%$ of these, past or present water damage and, in $46 \%$, past or present moisture stains were reported by the occupants. Significantly more of the "moisture present" houses were built commercially by a construction company rather than privately by the owner $(p<0.001)$. The baseline characteristics of the occupants exposed to moisture $(n=366)$ and the nonexposed $(n=333)$ occupants are presented in table 2 . In all, more than half $(52 \%)$ of the adults were living in houses in which they were exposed to moisture. There were no significant differences in atopic predisposition or doctor-diagnosed allergies between the exposed and nonexposed groups.

The proportions of adults with at least one episode of respiratory or nonrespiratory illness and adjusted odds ratios (ORs) with 95\% confidence intervals for the association between observed moisture at home and respiratory and nonrespiratory illnesses are shown in table 3 . A total of 22 health outcomes were studied. For 19 health outcomes, the proportion of those with the illness was higher in the exposed adults than in the respective nonexposed individuals. After adjustment, the ORs were $>1$ among the exposed adults for 20 health outcomes. The risk of respiratory infections, such as sinusitis $(\mathrm{OR}=1.92)$ and acute bronchitis $(\mathrm{OR}=1.98)$, was significantly increased. Significantly increased risks of nocturnal cough $(\mathrm{OR}=2.11)$, nocturnal dyspnoea $(\mathrm{OR}=2.33)$ and sore throat $(\mathrm{OR}=$ 1.46) were also found in the exposed group. Furthermore, 
Table 1. - Characteristics of the houses with and without observations of moisture

\begin{tabular}{lcc}
\hline & $\begin{array}{c}\text { Moisture absent } \\
\text { n (\%) }\end{array}$ & $\begin{array}{c}\text { Moisture present } \\
\text { n (\%) }\end{array}$ \\
\hline Houses n & 150 & 160 \\
Detached house & $124(83)$ & $128(80)$ \\
Terraced house & $26(17)$ & $32(20)$ \\
Owner-occupied house & $148(99)$ & $155(98)$ \\
Age of dwelling <25 yrs & $113(75)$ & $105(66)$ \\
Living area ${ }^{2}$ & 121 & 124 \\
Owner-built house $_{\text {Water damage }}^{\S}$ & $91(64)^{* * *}$ & $62(41)$ \\
Moisture stains & $69(46)^{* * *}$ & $138(86)$ \\
Humidifier & $34(23)^{* * *}$ & $79(49)$ \\
Air cleaner & $33(22)$ & $32(20)$ \\
Smoking in the house & $14(9)^{*}$ & $6(2)$ \\
\hline
\end{tabular}

s: reported by the occupants; ${ }^{+}$: air filter or air purifier (portable).

$*$ : $\mathrm{p}<0.05 ; * * *: \mathrm{p}<0.001$.

the exposed individuals suffered on average 2.0 episodes of common cold and 2.3 episodes of tonsillitis, whereas the nonexposed suffered 1.7 and 1.1 episodes respectively of these illnesses. The differences were statistically significant $(\mathrm{p}<0.05)$. There were no significant differences between the groups on the basis of sick leave or doctor visits nor were there any significant differences in nonrespiratory illnesses between the groups.

In the second phase, exposure was defined as "mould present" or "mould absent", as reported by the occupants. The characteristics of the houses with occupant reported observations of mould, i.e. "mould present" $(n=84)$, and with no observations of mould, i.e. "mould absent" ( $\mathrm{n}=$ 226), are presented in table 4 . Mould was reported by the occupants of $27 \%$ of the houses. In $29(9 \%)$ houses, mould was reported to be present by the inhabitants, although no moisture was observed by the surveyor. Of the "mould present" houses, $81 \%$ had past or present water damage and $53 \%$ had past or present moisture stains, as reported by the occupants. The houses with reported observations of mould were significantly larger in surface area than the houses with no reported observations of mould $(\mathrm{p}<0.05)$. The baseline characteristics of the occupants exposed to mould $(\mathrm{n}=189)$ and nonexposed occupants $(n=510)$ are presented in table 5. In all, almost one-third $(27 \%)$ of the adults were living in houses in

Table 2. - Baseline characteristics of the occupants in houses with and without observations of moisture

\begin{tabular}{lcc}
\hline & $\begin{array}{c}\text { Moisture absent } \\
\mathrm{n}(\%)\end{array}$ & $\begin{array}{c}\text { Moisture present } \\
\mathrm{n}(\%)\end{array}$ \\
\hline Occupants n & 333 & 366 \\
Male sex & $162(49)$ & $184(50)$ \\
Mean age yrs & 46.5 & 45.9 \\
Asthma & $28(9)$ & $24(7)$ \\
Atopic predisposition & $99(31)$ & $132(38)$ \\
Allergy & $54(17)$ & $66(19)$ \\
Smoking & $48(20)$ & $44(18)$ \\
Passive smoking & $61(19)$ & $68(20)$ \\
Pets living indoors & $116(35)$ & $139(38)$ \\
Regular need for & $117(36)$ & $113(32)$ \\
$\quad$ medication & & \\
Handling of mouldy & $85(27)$ & $104(30)$ \\
$\quad$ material & & \\
\hline
\end{tabular}

Table 3. - The proportions of occupants with respiratory or nonrespiratory illnesses and adjusted ${ }^{+}$odds ratios (ORs) for the association between moisture at home and the occupants' respiratory and nonrespiratory illnesses in the past 12 months

\begin{tabular}{lcccc}
\hline & $\begin{array}{c}\text { Moisture } \\
\text { absent } \\
\text { n (\%) }\end{array}$ & $\begin{array}{c}\text { Moisture } \\
\text { present } \\
\text { n (\%) }\end{array}$ & OR & $95 \%$ CI \\
\hline Occupants n & 333 & 366 & & \\
Common cold & $204(61)$ & $229(63)$ & 1.11 & $0.79-1.56$ \\
Tonsillitis & $12(4)$ & $22(6)$ & 1.79 & $0.79-4.07$ \\
Otitis & $15(5)$ & $9(2)$ & 0.60 & $0.25-1.41$ \\
Sinusitis & $28(8)$ & $41(11)$ & 1.92 & $1.11-3.30$ \\
Bronchitis & $24(7)$ & $45(12)^{*}$ & 1.98 & $1.13-3.48$ \\
Cough without & $49(15)$ & $67(18)$ & 1.42 & $0.92-2.19$ \\
$\quad$ phlegm & & & & \\
Cough with & $75(23)$ & $87(24)$ & 1.15 & $0.78-1.69$ \\
phlegm & & & & \\
Nocturnal cough & $24(7)$ & $44(12)^{*}$ & 2.11 & $1.21-4.98$ \\
Nocturnal & $13(4)$ & $25(7)$ & 2.33 & $1.09-4.98$ \\
$\quad$ dyspnoea & & & & \\
Hoarseness & $139(42)$ & $171(47)$ & 1.30 & $0.93-1.81$ \\
Sore throat & $165(50)$ & $210(57)^{*}$ & 1.46 & $1.03-2.08$ \\
Rhinitis & $230(69)$ & $259(71)$ & 1.06 & $0.71-1.59$ \\
Nasal bleeding & $25(16)$ & $55(15)$ & 0.94 & $0.62-1.42$ \\
Impaired sense & $51(15)$ & $67(18)$ & 1.23 & $0.80-1.91$ \\
$\quad$ of smell & & & & \\
Eczema & $78(23)$ & $86(23)$ & 1.03 & $0.71-1.49$ \\
Atopic eczema & $55(17)$ & $66(18)$ & 1.18 & $0.76-1.83$ \\
Allergic eczema & $39(12)$ & $45(12)$ & 1.06 & $0.64-1.78$ \\
Eye irritation & $113(34)$ & $129(35)$ & 1.08 & $0.76-1.53$ \\
Nausea & $76(23)$ & $93(25)$ & 1.23 & $0.85-1.80$ \\
Headache & $209(63)$ & $237(65)$ & 1.24 & $0.85-1.81$ \\
Fatigue & $259(78)$ & $301(82)$ & 1.50 & $0.88-2.56$ \\
Difficulties in & $118(35)$ & $148(40)$ & 1.24 & $0.88-1.74$ \\
$\quad$ concentration & & & & \\
\hline & & & & \\
t. & & &
\end{tabular}

${ }^{+}$: adjusted for smoking, age, sex, allergy, indoor pets and atopic predisposition. CI: confidence interval. *: $\mathrm{p}<0.05$.

which they were exposed to mould. In the mould-exposed individuals, atopic predisposition $(\mathrm{p}<0.001)$ and doctor diagnosed allergies $(p<0.05)$ were significantly more common than in the nonexposed individuals.

The proportions of the occupants with at least one episode of respiratory or nonrespiratory illness and adjusted ORs with 95\% confidence intervals for the association

Table 4. - Characteristics of the houses with and without reported mould

\begin{tabular}{lcc}
\hline & $\begin{array}{c}\text { Moisture absent } \\
\mathrm{n}(\%)\end{array}$ & $\begin{array}{c}\text { Moisture present } \\
\mathrm{n}(\%)\end{array}$ \\
\hline Houses n & 226 & 84 \\
Detached house & $184(81)$ & $68(81)$ \\
Terraced house & $42(19)$ & $16(19)$ \\
Owner-occupied house & $222(99)$ & $81(96)$ \\
Age of dwelling $<25$ yrs & $160(71)$ & $58(69)$ \\
Living area ${ }^{2}$ & $119^{*}$ & 130 \\
Owner-built house & $118(53)$ & $35(46)$ \\
Water damage & $139(62)^{* *}$ & $68(81)$ \\
Moisture stains & $69(31)^{* * *}$ & $44(53)$ \\
Humidifier & $51(23)$ & $14(17)$ \\
Air cleaner & $16(7)$ & $4(5)$ \\
Smoking in the house & $26(12)$ & $9(11)$ \\
\hline${ }^{+}:$air filter or air purifier (portable). ${ }^{*}: \mathrm{p}<0.05 ; * *: \mathrm{p}<0.01 ; * * *$ \\
p $<0.001$.
\end{tabular}


Table 5. - Baseline characteristics of the occupants of houses with and without reported mould

\begin{tabular}{lcc}
\hline & $\begin{array}{c}\text { Moisture absent } \\
\mathrm{n}(\%)\end{array}$ & $\begin{array}{c}\text { Moisture present } \\
\mathrm{n}(\%)\end{array}$ \\
\hline Occupants $\mathrm{n}$ & 510 & 189 \\
Male sex & $256(50)$ & $90(48)$ \\
Mean age yrs & 46.7 & 44.9 \\
Asthma & $34(7)$ & $18(10)$ \\
Atopic predisposition & $148(31)^{* * *}$ & $83(45)$ \\
Allergy & $78(16)^{*}$ & $42(23)$ \\
Smoking & $100(21)$ & $27(15)$ \\
Passive smoking & $93(19)$ & $36(20)$ \\
Pets living indoors & $180(35)$ & $75(40)$ \\
Regular need for & $175(36)$ & $55(30)$ \\
$\quad$ medication & & \\
Handling of mouldy & $132(28)$ & $57(31)$ \\
$\quad$ material & & \\
\hline
\end{tabular}

$*: \mathrm{p}<0.05 ; * * *: \mathrm{p}<0.001$.

between occupant-reported mould at home and respiratory and nonrespiratory illnesses are shown in table 6 . In 20 of the 22 health outcomes studied, the proportions of those with the illness was higher in the exposed adults then in the respective nonexposed individuals. After adjustment, the ORs were $>1$ for 21 health outcomes among the adults exposed to mould. Significantly increased risks for com-

Table 6. - The proportions of the occupants with respiratory or nonrespiratory illnesses and adjusted ${ }^{+}$odds ratios (ORs) for the association between mould at home and occupants' respiratory and nonrespiratory illnesses in the past 12 months

\begin{tabular}{|c|c|c|c|c|}
\hline & $\begin{array}{c}\text { Moisture } \\
\text { absent } \\
\text { n (\%) }\end{array}$ & $\begin{array}{c}\text { Moisture } \\
\text { present } \\
\text { n (\%) }\end{array}$ & OR & $95 \% \mathrm{CI}$ \\
\hline Occupants $n$ & 510 & 189 & & \\
\hline Common cold & $298(58)$ & $135(71)^{* *}$ & 1.62 & $1.08-2.41$ \\
\hline Tonsillitis & $21(4)$ & $13(7)$ & 1.38 & $0.61-3.11$ \\
\hline Otitis & $14(3)$ & $10(5)$ & 1.08 & $0.87-4.90$ \\
\hline Sinusitis & $46(9)$ & $23(12)$ & 1.36 & $0.78-2.39$ \\
\hline Bronchitis & $43(8)$ & $26(14)$ & 1.68 & $0.95-2.95$ \\
\hline $\begin{array}{l}\text { Cough without } \\
\text { phlegm }\end{array}$ & $116(23)$ & $39(21)$ & 1.60 & $1.01-2.53$ \\
\hline $\begin{array}{l}\text { Cough with } \\
\text { phlegm }\end{array}$ & $109(21)$ & $53(28)$ & 1.44 & $0.95-2.19$ \\
\hline $\begin{array}{l}\text { Nocturnal } \\
\text { cough }\end{array}$ & $38(7)$ & $30(16)^{* *}$ & 2.30 & $1.32-4.01$ \\
\hline $\begin{array}{l}\text { Nocturnal } \\
\text { dyspnoea }\end{array}$ & $25(5)$ & $13(7)$ & 1.58 & $0.74-3.39$ \\
\hline Hoarseness & $210(41)$ & $100(53)^{* *}$ & 1.44 & $0.99-2.10$ \\
\hline Sore throat & $247(48)$ & $128(68)^{* * *}$ & 2.40 & $1.56-3.69$ \\
\hline Rhinitis & $207(41)$ & $100(53)^{* *}$ & 1.89 & $1.15-3.11$ \\
\hline Nasal bleeding & 73 (14) & $35(19)$ & 1.27 & $0.80-2.04$ \\
\hline $\begin{array}{l}\text { Impaired sense } \\
\text { of smell }\end{array}$ & 81 (16) & $37(20)$ & 1.28 & $0.80-2.06$ \\
\hline Eczema & $111(22)$ & $53(28)$ & 1.40 & $0.93-2.10$ \\
\hline Atopic eczema & $80(16)$ & $41(22)$ & 1.18 & $0.73-1.90$ \\
\hline Allergic eczema & 64 (13) & $20(11)$ & 0.77 & $0.43-1.38$ \\
\hline Eye irritation & $116(23)$ & $79(42)^{* * *}$ & 1.43 & $0.84-1.83$ \\
\hline Nausea & $115(23)$ & $54(29)$ & 1.36 & $0.90-2.06$ \\
\hline Headache & $306(60)$ & $140(74)^{*}$ & 1.52 & $0.98-2.36$ \\
\hline Fatigue & $392(77)$ & $168(89)^{* *}$ & 3.97 & $1.67-9.46$ \\
\hline $\begin{array}{l}\text { Difficulties in } \\
\text { concentration }\end{array}$ & $180(35)$ & $86(46)^{*}$ & 1.45 & $1.00-2.12$ \\
\hline
\end{tabular}

mon cold $(\mathrm{OR}=1.62)$, cough without phlegm $(\mathrm{OR}=1.60)$, nocturnal cough $(\mathrm{OR}=2.30)$, sore throat $(\mathrm{OR}=2.40)$ and rhinitis $(\mathrm{OR}=1.89)$ were associated with exposure to mould. Furthermore, the exposed occupants had significantly increased risks of fatigue $(\mathrm{OR}=3.97)$ and difficulties in concentration $(\mathrm{OR}=1.45)$. There were no significant differences between the exposure groups on the basis of sick leave or doctor visits.

\section{Discussion}

Increased morbidity among adults was associated both with exposure to moisture and with exposure to mould in the home environment. The statistically significant ORs ranged 1.45-3.97 for respiratory and nonrespiratory illnesses. This range of risks is high compared to that of other environmental exposures, such as environmental tobacco smoke or outdoor air pollutants [19].

The risk of respiratory infections was significantly increased with exposure to moisture. Furthermore, the number of episodes of respiratory infection was significantly higher. Exposure to mould was a risk factor for common cold. This association between respiratory infections and exposure to moisture or mould has previously been reported for children [4, 20-22] but, as far as adults are concerned, this is a new finding.

Significantly increased risks of respiratory symptoms, such as sore throat, nocturnal cough and nocturnal dyspnoea were associated with exposure to moisture, whereas exposure to mould increased the risks of rhinitis, sore throat, cough without phlegm and nocturnal cough. Among the upper respiratory tract symptoms, blocked nose in adults has been reported previously $[5,10]$, but sore throat only for children $[5,20]$. Cough has frequently been associated with home dampness $[5,7,10]$. as well as breathlessness $[1,5]$. However, nocturnal cough and nocturnal dyspnoea associated with exposure to moisture is a new finding. Dyspnoea is considered to be the result of a complex interaction of signals involving the central nervous system and receptors in the airways [23]. Thus, exposure to moisture could cause dyspnoea by a variety of mechanisms. The risk of nocturnal dyspnoea was not, however, significantly increased when the exposure was defined as "mould", but there was increased risk of nocturnal cough and cough without phlegm. Although the classical symptoms of asthma include cough, dyspnoea and wheezing, there appear to be asthmatics whose asthma is characterized solely by cough without wheezing [24]. No excess wheezing was found in the present study, but the nocturnal cough and dyspnoea reported here may be a harbinger of asthma. There was no difference in the prevalence of asthma between the groups at the time of the study, and therefore this finding should be verified with a more focused study.

The risk of nonrespiratory symptoms, such as fatigue and concentration difficulties, was significantly increased in adults exposed to mould. Similar findings have been reported by PirHONEN et al. [11]. Although significantly increased morbidity was associated with exposure to moisture or mould, there were no significant differences in doctor visits or sick leave between the exposed and nonexposed groups. This result may be related to the readily available healthcare services, which may lead to physicians being visited for even minor health problems. 
In this study, based on a random sample, the response rate reached $100 \%$, which minimizes the possibility of selection bias and increases the validity of the study. The health data were collected before the site visit by a surveyor. None of the health outcomes were eventually considered as control questions for possible reporting bias. Symptoms widely used as controls in questionnaire studies, such as backache or stomach ache, have been associated with moisture or mould $[5,8,10,11]$. Several confounding factors were controlled for in the logistic regression analysis. There are, however, other variables which may be risk factors for the health outcomes studied. Ambient air pollution is a known risk factor for respiratory illnesses, but, in Finland, ambient air quality is good in comparison with larger central European cities [25]. As for possible occupational mould exposure, the study material did not include houses from rural areas or farms. The influence of socioeconomic factors was reduced, as practically all the houses were owner-occupied. The houses with moisture or mould were even larger than the reference houses, and thus the increased morbidity was not due to overcrowding. Moisture observations were significantly more common in houses built by a construction company than in owner-built houses. It may be assumed that more effort is put into the maintenance of these selfbuilt houses.

In this study, $52 \%$ of the houses had a current moisture problem, as assessed by a building professional. In the Scandinavian climate, indoor relative humidity ranges 10 $20 \%$ in winter and $20-40 \%$ in summer [13]. Thus, microbial growth and related indoor air contaminants are not caused by general dampness but are a consequence of water condensing or leaking into the structures. Of the "moisture present" houses, only $49 \%$ were reported as having past or present moisture stains by the occupants, which means that only half of the occupants were aware of the moisture problem in their own house. Evidently, the signs of moisture were underestimated by the inhabitants.

The occupants reported the presence of mould in $27 \%$ of the houses. In $9 \%$ of the houses, mould was reported by the occupants, although no moisture was observed by the surveyor. Thus, there was not perfect agreement between the observations of the surveyor and those of the occupants. In another random sample of the adult population in Finland, moisture stains, visible mould or mould odour were reported by $15 \%$ but visible mould only by $6 \%$ of the respondents [11]. The previously reported prevalences of occupant-assessed moisture, damp or mould have been up to $39 \%$ and the prevalences of mould up to $15 \%[3,6-8$, 22]. Self-reporting of mould is subjective, but, on the other hand, the occupants know the history of the house and recall incidents from a longer period of time. The occurrence of water damage at some time in the past may be important for exposure if it leads to hidden mould growth within building constructions. The definition of exposure associated with moisture damage of a building is still a multifaceted issue. At what stage moisture problem develops into a mould problem is the sum of many technical and microbiological/ecological factors.

In conclusion, the results show that exposure to building-related moisture or mould in the home is a significant risk factor for respiratory infections, respiratory symptoms and nonrespiratory illnesses in adults.

\section{References}

1. Burr ML, St Leger AS, Yarnell JWG. Wheezing, dampness, and coal fires. Comm Med 1981; 3: 205-209.

2. Martin CJ, Platt SD, Hunt SM. Housing conditions and ill health. Br Med J 1987; 294: 1125-1127.

3. Burr ML, Mullins J, Merrett TG, et al. Indoor moulds and asthma. JRSH 1988; 3: 99-101.

4. Waegemaekers M, van Wageningen N, BrunekreefB, etal. Respiratory symptoms in damp houses. Allergy 1989;44: 192-198.

5. Platt SD, Martin CJ, Hunt SM, et al. Damp housing, mould growth and symptomatic health state. Br Med J 1989; 298: 1673-1989.

6. Dales RE, Burne R, Zwanenburg H. Adverse health effects among adults exposed to home dampness and moulds. Am Rev Respir Dis 1991; 143: 505-509.

7. Brunekreef B. Damp housing and adults respiratory symptoms. Allergy 1992; 47: 498-502.

8. Packer CN, Stewart-Brown S, Fowle SE. Damp housing and adult health: results from a lifestyle study in Worcester, England. J Epidemiol Community Health 1994; 48: 555-559.

9. Björnsson E, Norbäck D, Janson C, et al. Asthmatic symptoms and indoor levels of micro-organisms and house dust mites. Clin Exp Allergy 1995; 25: 423-431.

10. Hyndman SJ. Housing dampness and health amongst British Bengalis in east London. Soc Sci Med 1990; 30: 131-141.

11. Pirhonen I, Nevalainen A, Husman T, Pekkanen J. Home dampness, moulds and their influence on respiratory infections and symptoms in adults in Finland. Eur Respir J 1996; 9: 2618-2622.

12. Hu FB, Persky V, Flay BR, Phil D, Richardson J. An epidemiological study of asthma prevalence and related factors among young adults. Journal of Asthma 1997; 34: 67-76.

13. Flannigan B, Morey PR. Control of moisture problems affecting biological indoor air quality. ISIAQ Guideline: Task force I-1996. ISIAQ 1996, Canada.

14. Hyvärinen A, Reponen T, Husman T, Ruuskanen J, Nevalainen A. Characterizing mould-problem buildings - concentrations and flora of viable fungi. Indoor Air 1993; 3: 337-343

15. Nevalainen A, Husman T, Hyvärinen A, et al. Prevalence of moisture problems in Finnish houses. Indoor Air 1998; Suppl. 4: 45-49.

16. Koskinen OM, Husman TM, Meklin TM, Nevalainen AL. Adverse health effects in children associated with moisture and mould observations in houses. Int J Env Health Res 1999; 9: 143-156.

17. Husman T. Hengitystiesairaudet ja -oireet neljällä eteläSuomen paikkakunnalla: yhteys altistumiseen ilman saasteille. (Ambient air pollution and respiratory symptoms and diseases). Helsinki 1995, Helsinki University, Academic dissertation.

18. Kuusisto P. Ulkoilma ja astma. Astmahavaintojen yhteys säähän, siitepölyihin, itiöihin, rikkidioksidiin ja leijuvaan pölyyn. (Outdoor air and asthma). Helsinki 1990, Helsinki University, Academic dissertation.

19. Peat JK, Dickerson J, Li J. Effects of damp and mould in the home on respiratory health: a review of the literature. Allergy 1998; 53: 120-128.

20. Koskinen O, Husman T, Hyvärinen A, et al. Respiratory symptoms and infections among children in a day-care center with mould problem. Indoor Air 1995; 3: 3-9.

21. Brunekreef B, Dockery DW, Speizer FE, et al. Home dampness and respiratory morbidity in children. Am Rev Respir Dis 1989; 140: 1363-1367.

22. Dales RE, Zwanenburg H, Burnett R, et al. Respiratory health effects of home dampness and moulds among Canadian children. Am J Epidemiol 1991; 134: 196-203.

23. Manning HL, Schwartzstein RM. Pathophysiology of dyspnea. N Engl J Med 1995; 333: 1547-1554.

24. Kaliner M, Lemanske R. Rhinitis and asthma. JAMA 1992; 268: 2807-2828

25. Hoek G, Brunekreef B, Clench-Aas J, et al. PEACE study. (2) Exposure Assessment. Epidemiology 1995; 6: S65. 